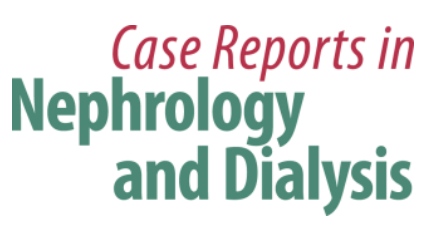

Case Rep Nephrol Dial 2019;9:25-32

DOI: 10.1159/000499401

Published online: April 16, 2019

(c) 2019 The Author(s)

Published by S. Karger AG, Basel

www.karger.com/cnd

This article is licensed under the Creative Commons Attribution-NonCommercial 4.0 International License (CC BY-NC) (http://www.karger.com/Services/OpenAccessLicense). Usage and distribution for commercial purposes requires written permission.

\title{
Rapidly Progressive \\ Glomerulonephritis with Delayed Appearance of Anti-Glomerular Basement Membrane Antibody Successfully Treated with Multiple Courses of Steroid Pulse Therapy
}

\author{
Satoshi Toyota ${ }^{a}$ Masahiro Eriguchi ${ }^{a}$ Shoko Hasegawa ${ }^{a}$ Kenji Ueki ${ }^{a}$ \\ Yuta Matsukuma $^{a}$ Akihiro Tsuchimoto ${ }^{a}$ Kiichiro Fujisaki ${ }^{a}$ \\ Kumiko Torisu ${ }^{a}$ Kazuhiko Tsuruya ${ }^{c}$ Toshiaki Nakano ${ }^{a, b}$ \\ Takanari Kitazono ${ }^{\mathrm{a}}$ \\ aDepartment of Medicine and Clinical Science, Graduate School of Medical Sciences,

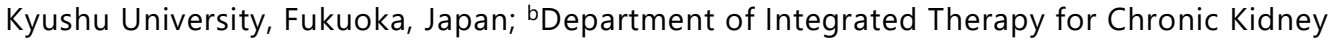 \\ Disease, Graduate School of Medical Sciences, Kyushu University, Fukuoka, Japan; \\ 'Department of Nephrology, Nara Medical University, Kashihara, Japan
}

\section{Keywords}

Rapidly progressive glomerulonephritis - Delayed appearance of antibody · Anti-glomerular basement membrane antibody $\cdot$ Immunoglobulin $\mathrm{G}$ subclass

\begin{abstract}
Patients with anti-glomerular basement membrane (GBM) antibody glomerulonephritis typically exhibit rapidly progressive glomerulonephritis (RPGN). The renal outcome as well as the prognosis of this disease is worse than other forms of RPGN such as those from microscopic polyangiitis. Therefore, early therapeutic intervention is essential to improve its prognosis. One month before referral to our hospital, a 54-year-old female attended another hospital because of macrohematuria. At that time, she had proteinuria and macrohematuria with normal renal
\end{abstract}




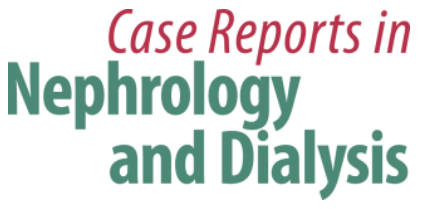

Case Rep Nephrol Dial 2019;9:25-32

DOI: 10.1159/000499401

(c) 2019 The Author(s). Published by S. Karger AG, Basel www.karger.com/cnd

Toyota et al.: Nephritis with Delayed Appearance of Anti-Glomerular Basement Membrane Antibody

function, was negative for anti-GBM antibodies, and was diagnosed with chronic glomerulonephritis. A month later when she was admitted to our hospital, she showed renal insufficiency and was positive for anti-GBM antibodies. Immediately after recognizing the anti-GBM antibody status, plasma exchange and the first course of steroid pulse therapy was started. After 5 days of therapy, renal biopsy confirmed severe crescentic glomerulonephritis in which all the observed glomeruli were involved with cellular crescents. Despite this, she survived without end-stage renal disease after three courses of steroid pulse therapy and seven sessions of plasma exchange. This favorable outcome reflects the repeated analysis of anti-GBM antibodies within a very short period and the rapid therapeutic intervention in addition to the intensive immunosuppressive therapies.

(C) 2019 The Author(s)

Published by S. Karger AG, Basel

\section{Introduction}

Anti-glomerular basement membrane (GBM) disease is characterized by crescentic glomerulonephritis with the pathological finding of linear IgG deposition along the GBM [1]. Immunological findings revealed that specific antibody epitopes are hidden parts of the noncollagenous- 1 domain of alpha- 3 and -5 chains of type IV collagen, which are occasionally exposed by infection, smoking, and toxic substances [2]. In terms of the pathological pathway, anti-GBM antibody binding induces the accumulation of inflammatory cells and cytokines, resulting in rupture of the GBM. Subsequently, the leakage of fibrin and inflammatory cells outside the Bowman's capsule mediates epithelial cell proliferation and crescent formation.

Clinically, most patients display rapidly progressive glomerulonephritis (RPGN), in which renal failure progresses very rapidly, resulting in end-stage renal disease in two-thirds of patients after 6 months of follow-up despite modern treatments [1]. Therefore, a prompt diagnosis and the immediate initiation of treatment are essential [1]. In this report, we describe a rare case in which we initiated intensive immunosuppressive treatment immediately after recognizing the positive anti-GBM antibody status that had been negative 1 month previously. Renal function was preserved without the need for renal replacement therapies, even though all the observed glomeruli were affected by crescent formation.

\section{Case Report}

A 54-year-old female with no medical history noticed dark urine 8 weeks before admission to our hospital, and high fever $\left(>38^{\circ} \mathrm{C}\right)$ appeared 2 weeks later. She was admitted to another hospital 4 weeks before referral to our hospital. At that time, she showed macrohematuria and proteinuria (urinary protein/urinary creatinine ratio: Up/Ucr $2.0 \mathrm{~g} / \mathrm{gCr}$ ), and her serum creatinine level was $0.88 \mathrm{mg} / \mathrm{dL}$. She did not have edema and her body weight remained unchanged as before and was $81 \mathrm{~kg}$. Accounting for the creatinine production level estimated by her body weight, her renal function was supposed to be normal. Both anti-GBM (3.2 U/mL; minimal detection level $7 \mathrm{U} / \mathrm{mL}$, BML, Tokyo, Japan) and anti-ANCA antibodies were negative. Antibiotics had no effect on her fever and serum complement levels were normal (C3 $195 \mathrm{mg} / \mathrm{dL}$, C4 $54.6 \mathrm{mg} / \mathrm{dL}, \mathrm{CH} 50101 \mathrm{U} / \mathrm{mL}$ ). She was diagnosed with chronic glomerulonephritis and referred to our hospital for renal biopsy.

On admission, her vital signs were as follows: body temperature, $37.1^{\circ} \mathrm{C}$; blood pressure, 146/96 mm Hg; heart rate, 81 beats/min; $\mathrm{SpO}_{2}, 98 \%$ (room air). There was no peripheral 


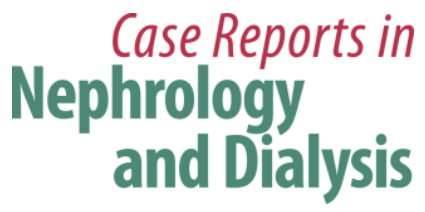

Case Rep Nephrol Dial 2019;9:25-32

DOI: 10.1159/000499401

(c) 2019 The Author(s). Published by S. Karger AG, Basel www.karger.com/cnd

Toyota et al.: Nephritis with Delayed Appearance of Anti-Glomerular Basement Membrane Antibody

edema and her urine volume was $2,000 \mathrm{~mL} /$ day. Other physical examinations including otorhinolaryngology were normal. Chest X-ray and computed tomography showed no alveolar hemorrhage or interstitial pneumonia.

She displayed renal dysfunction (blood urea nitrogen, $27 \mathrm{mg} / \mathrm{dL}$; serum creatinine, 1.62 $\mathrm{mg} / \mathrm{dL}$ ), and had persistent macrohematuria and proteinuria (Up/Ucr $3.06 \mathrm{~g} / \mathrm{gCr}$ ). Her hemoglobin level was $9.4 \mathrm{~g} / \mathrm{dL}$, and C-reactive protein (CRP) level was $13.98 \mathrm{mg} / \mathrm{dL}$. As RPGN was highly suspected at this point, we repeatedly measured anti-GBM antibodies on the first day of admission and obtained a positive result $(52.6 \mathrm{U} / \mathrm{mL}$; minimal detection level $3 \mathrm{U} / \mathrm{mL}$, SRL, Tokyo, Japan) on the third hospital day. We also repeatedly measured anti-ANCA antibodies (MPO and PR3) and confirmed these were negative. At that time, she had further increase in serum creatinine level $(1.62 \mathrm{mg} / \mathrm{dL}$ to $2.00 \mathrm{mg} / \mathrm{dL})$. Immediately after recognizing the antiGBM antibody-positive status, we started methylprednisolone pulse therapy $(1 \mathrm{~g} /$ day for 3 days) and plasma exchange (seven sessions for 3 weeks) (Fig. 1). We treated this patient with plasma exchange using 5\% albumin instead of fresh-frozen plasma as volume replacement, which is associated with fewer adverse reactions than plasma exchange using fresh-frozen plasma as previously described [3]. Also, we adjusted the frequency of plasma exchange (less than 3 sessions per week) and kept the patient's fibrinogen level to more than $200 \mathrm{mg} / \mathrm{dL}$ to avoid hemorrhagic complication.

On the eighth hospital day, we performed renal biopsy to confirm crescentic glomerulonephritis. Renal biopsy specimens included 16 glomeruli of which six were global sclerosis and four were segmental sclerosis; cellular crescents were present in all glomeruli with or without glomerular sclerosis (Fig. 2a and b). Inflammatory cell infiltration was detected in over $50 \%$ of the renal interstitium with moderate to severe interstitial fibrosis and tubular atrophy (Fig. 2c and d). Linear IgG depositions were detected along the glomerular capillaries, which was compatible with anti-GBM glomerulonephritis (Fig. 2e). To gain further insight into IgG deposition on GBM, we examined IgG subclass in the glomeruli. As shown in Figure $2 \mathrm{f}-\mathrm{i}$, IgG1 subclass is predominant in the glomeruli. We also confirmed IgG4 is negative in the glomeruli. Indeed, her HbA1c (NGSP) level is $6.7 \%$ on admission to our hospital. Her diabetes vintage was unclear, because she had never received a health checkup. However, she did not have any diabetic neuropathy including autonomic neural dysfunction as well as diabetic retinopathy. Furthermore, light microscopic examination of renal biopsy did not show any diabetic change in the vessels (hyalinosis) and glomeruli (mesangial expansion). In this case, linear IgG deposition on GBM (Fig. 2e-i) was not associated with diabetic nephropathy, in which faint linear IgG deposition on GBM is sometimes observed. During steroid treatment, she did not require any anti-diabetic drugs or insulin.

After the first course of steroid pulse therapy, macrohematuria, high fever, and elevated CRP were temporarily improved. However, with the daily administration of $40 \mathrm{mg}$ oral prednisolone, macrohematuria appeared again and the patient's body temperature and CRP were gradually elevated within 2 weeks (Fig. 1). From the 16th hospital day, she was repeatedly treated with a second course of steroid pulse therapy ( $1 \mathrm{~g} /$ day for 3 days), and the dose of oral prednisolone administration was increased to $60 \mathrm{mg} /$ day. These abnormalities were rapidly reversed after the second course of steroid pulse therapy, but again relapsed with 2 weeks of oral prednisolone (Fig. 1). From the 30th hospital day, a third course of steroid pulse therapy (500 mg/day for 3 days) was performed, and the patient responded rapidly. She was successfully treated with oral prednisolone with cyclophosphamide after the third steroid pulse therapy. The titer of anti-GBM antibody and serum creatinine was gradually decreased from 87.3 $\mathrm{U} / \mathrm{mL}$ and $6.33 \mathrm{mg} / \mathrm{dL}$ to $12.2 \mathrm{U} / \mathrm{mL}$ and $3.01 \mathrm{mg} / \mathrm{dL}$, respectively, at the time of discharge 


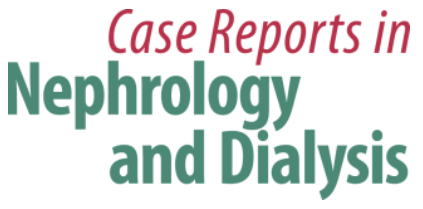

Case Rep Nephrol Dial 2019;9:25-32

DOI: 10.1159/000499401

(c) 2019 The Author(s). Published by S. Karger AG, Basel www.karger.com/cnd

Toyota et al.: Nephritis with Delayed Appearance of Anti-Glomerular Basement Membrane Antibody

(Fig. 1). Thirteen months after discharge form our hospital, she remained stable on renal function and negative anti-GBM antibody status $(<2.0 \mathrm{U} / \mathrm{mL})$ with the daily administration of 10 $\mathrm{mg}$ oral prednisolone. She did not have hematuria (1-4/HPF) nor overt proteinuria (Up/Ucr 0.37). Her serum creatinine level was $2.95 \mathrm{mg} / \mathrm{dL}$, which was comparable with the level at the time of discharge.

\section{Discussion}

Anti-GBM disease has a worse renal prognosis than other forms of RPGN [4]. Previous reports showed that a decrease in renal function at diagnosis, the percentage of crescent formation in glomeruli, and the anti-GBM antibody titer are important risk factors for renal prognosis [4-8]. In terms of renal dysfunction at diagnosis, oliguria [8] and/or serum creatinine $>500 \mu \mathrm{mol} / \mathrm{L}(>5.7 \mathrm{mg} / \mathrm{dL}$ ) [5, 8] and more than $30 \%$ [4] or 75\% [8] crescent formation were reported to be associated with poor renal prognosis. Indeed, Levy et al. [5] found that all patients who underwent immediate dialysis and had $100 \%$ crescent formation could not recover from dialysis dependence. The titer of the anti-GBM antibody is a good predictor of renal prognosis when patients are not initially dialysis dependent [6]. Because the level of renal dysfunction at diagnosis is associated not only with renal but also life prognosis, a rapid diagnosis and initiation of therapy are effective strategies at improving prognosis [6, 7]. In the present case, the patient survived without end-stage renal failure following the early initiation of immunosuppressive therapy, even though all glomeruli showed crescent formation.

Typically, the anti-GBM antibody titer is also a good indicator of disease activity [4, 9], but occasionally it cannot be detected in the early stages of disease [10-12]. In these cases, delays in appearance of anti-GBM antibodies in serum varied from 4 to 11 weeks [10-12]. In two out of three cases, only lung involvement was initially evident and the positive antibody status was associated with the onset of renal involvement $[10,12]$. Therefore, a delay in appearance of anti-GBM antibodies in serum mostly is associated with delayed renal involvement. Another important issue about detecting anti-GBM antibody is immunoglobulin G (IgG) subclass. Basically, IgG subclass of anti-GBM antibody is IgG1, as previously reported [13]. However, antiGBM antibody using enzyme linked immunosorbent assay (ELISA) reveals negative or borderline results in some cases with IgG2- and/or IgG4-restricted autoantibodies [14, 15]. Ossman et al. [15] reported that these patients could be confirmed by IgG4 anti-GBM ELISA or kidney biopsy and had relatively favorable renal outcome despite having severe alveolar hemorrhage in most cases $[14,15]$. In the present case, anti-GBM antibody ELISAs performed by different companies are basically the same. The epitopes of both assays are exactly the same, recombinant human noncollagenous domain 1 of type IV collagen of the alpha- 3 chain, but the minimal detection levels of the assays are different $(7 \mathrm{U} / \mathrm{mL}$ from BML, $3 \mathrm{U} / \mathrm{mL}$ from SRL). Also, the predominant subclass was IgG1, and IgG4 was negative, the same as usual cases. Putting together these results, we reached the clear conclusion that firstly negative antibody changed to positive subsequently. Despite having significant renal involvement (macrohematuria and proteinuria), the present case was initially negative for anti-GBM antibody at the time of stable renal function but became positive for the antibody after a rapid deterioration in renal function. This indicates that a negative antibody status can be seen with renal involvement and can change to a positive one even within a month.

Immunohistological analysis of a renal biopsy is the definitive means of diagnosing antiGBM antibody disease. However, it usually takes time to obtain the results of this analysis, and it is not always possible to perform a renal biopsy depending on the patient's condition. In our 


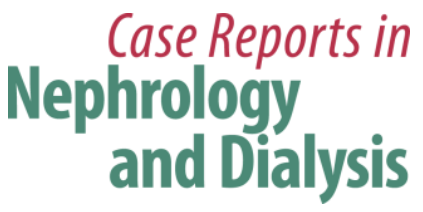

case, we tested the anti-GBM antibody status of the patient repeatedly over the course of a month and so could initiate intensive immunosuppressive therapy earlier than by performing a renal biopsy. This approach resulted in a favorable outcome in this case. Therefore, repeatedly testing the antibody status is recommended for patients in whom RPGN is highly suspected.

In summary, anti-GBM antibody glomerulonephritis rarely mimics chronic glomerulonephritis with normal renal function and negative antibody status in the very early stage of this disease and this negative antibody status can become positive within a month. Repeatedly testing the anti-GBM antibody status in a very short interval enabled us to initiate prompt intervention. As a result, the patient survived without end-stage renal disease after very intensive immunosuppressive therapies including three courses of steroid pulse therapy and seven sessions of plasma exchange, despite having $100 \%$ crescent formation in all the observed glomeruli.

\section{Acknowledgments}

We thank Sarah Williams, PhD, from Edanz Group (www.edanzediting.com) for editing a draft of the manuscript.

\section{Statement of Ethics}

Informed consent was obtained from all individual participants included in the study. All procedures performed in studies involving human participants were in accordance with the ethical standards of the institutional and/or national research committee at which the studies were conducted and with the 1964 Helsinki Declaration and its later amendments or comparable ethical standards. This article does not contain any studies with animals performed by any of the authors. The authors have no ethical conflicts to disclose.

\section{Disclosure Statement}

The authors have no conflicts of interest to declare.

\section{Funding Sources}

This study was not supported by any funding source.

\section{Author Contributions}

S.T., M.E., and T.N. conceived and designed the research; S.T., M.E., K.F., K.T., K.T., and T.N. performed the treatment; K.U, Y.M., and A.T. performed the histological diagnosis; M.E. and S.T. drafted the manuscript; S.T., M.E., S.H., Y.M., A.T., K.F., K.T., K.T., T.N., and T.K. edited and revised the manuscript. 


\section{Case Reports in Nephrology and Dialysis}

\begin{tabular}{l|l}
\hline DOI: $10.1159 / 000499401$ & (c) 2019 The Author(s). Published by S. Karger AG, Basel \\
\hline
\end{tabular}
www.karger.com/cnd

Toyota et al.: Nephritis with Delayed Appearance of Anti-Glomerular Basement Membrane Antibody

\section{References}

1 Hellmark T, Segelmark M. Diagnosis and classification of Goodpasture's disease (anti-GBM). J Autoimmun. 2014 Feb-Mar;48-49:108-12.

2 Pedchenko V, Bondar O, Fogo AB, Vanacore R, Voziyan P, Kitching AR, et al. Molecular architecture of the Goodpasture autoantigen in anti-GBM nephritis. N Engl J Med. 2010 Jul;363(4):343-54.

3 Mokrzycki MH, Kaplan AA. Therapeutic plasma exchange: complications and management. Am J Kidney Dis. 1994 Jun;23(6):817-27.

4 Johnson JP, Moore J Jr, Austin HA 3rd, Balow JE, Antonovych TT, Wilson CB. Therapy of anti-glomerular basement membrane antibody disease: analysis of prognostic significance of clinical, pathologic and treatment factors. Medicine (Baltimore). 1985 Jul;64(4):219-27.

5 Levy JB, Turner AN, Rees AJ, Pusey CD. Long-term outcome of anti-glomerular basement membrane antibody disease treated with plasma exchange and immunosuppression. Ann Intern Med. 2001 Jun;134(11):1033-42.

6 Segelmark M, Hellmark T, Wieslander J. The prognostic significance in Goodpasture's disease of specificity, titre and affinity of anti-glomerular-basement-membrane antibodies. Nephron Clin Pract. 2003;94(3):c5968.

7 Cui Z, Zhao J, Jia XY, Zhu SN, Zhao MH. Clinical features and outcomes of anti-glomerular basement membrane disease in older patients. Am J Kidney Dis. 2011 Apr;57(4):575-82.

8 Alchi B, Griffiths M, Sivalingam M, Jayne D, Farrington K. Predictors of renal and patient outcomes in antiGBM disease: clinicopathologic analysis of a two-centre cohort. Nephrol Dial Transplant. 2015 May;30(5):814-21.

9 Lockwood CM, Rees AJ, Pearson TA, Evans DJ, Peters DK, Wilson CB. Immunosuppression and plasmaexchange in the treatment of Goodpasture's syndrome. Lancet. 1976 Apr;1(7962):711-5.

10 Lettieri C, Pina J. Goodpasture's syndrome: a case of delayed appearance of autoantibodies and renal disease. Mil Med. 2001 Sep;166(9):827-30.

11 Gawryluk D, Baczkowska T, Pazik J, Wiatr E, Pawłowski J. [Recurrent alveolar hemorrhage in the course of Goodpasture's syndrome]. Pneumonol Alergol Pol. 2005;73(1):79-84.

12 Boardman EA, Sohail S, Yadavilli R. Goodpasture's disease with late presentation of renal abnormality and anti-GBM autoantibody. BMJ Case Rep. 2017 Mar 17;2017. pii: bcr2016218705.

13 Weber M, Lohse AW, Manns M, Meyer zum Büschenfelde KH, Köhler H. IgG subclass distribution of autoantibodies to glomerular basement membrane in Goodpasture's syndrome compared to other autoantibodies. Nephron. 1988;49(1):54-7.

14 Ohlsson S, Herlitz H, Lundberg S, Selga D, Mölne J, Wieslander J, et al. Circulating anti-glomerular basement membrane antibodies with predominance of subclass IgG4 and false-negative immunoassay test results in anti-glomerular basement membrane disease. Am J Kidney Dis. 2014 Feb;63(2):289-93.

15 Ossman R, Buob D, Hellmark T, Brocheriou I, Peltier J, Tamouza R, et al. Factors Associated With Pathogenicity of Anti-Glomerular Basal Membrane Antibodies: A Case Report. Medicine (Baltimore). 2016 May;95(19):e3654. 


\section{Case Reports in Nephrology and Dialysis}

\begin{tabular}{l|l}
\hline Case Rep Nephrol Dial 2019;9:25-32 \\
\hline DOI: 10.1159/000499401 & $\begin{array}{l}\text { @ 2019 The Author(s). Published by S. Karger AG, Basel } \\
\text { www.karger.com/cnd }\end{array}$ \\
\hline
\end{tabular}

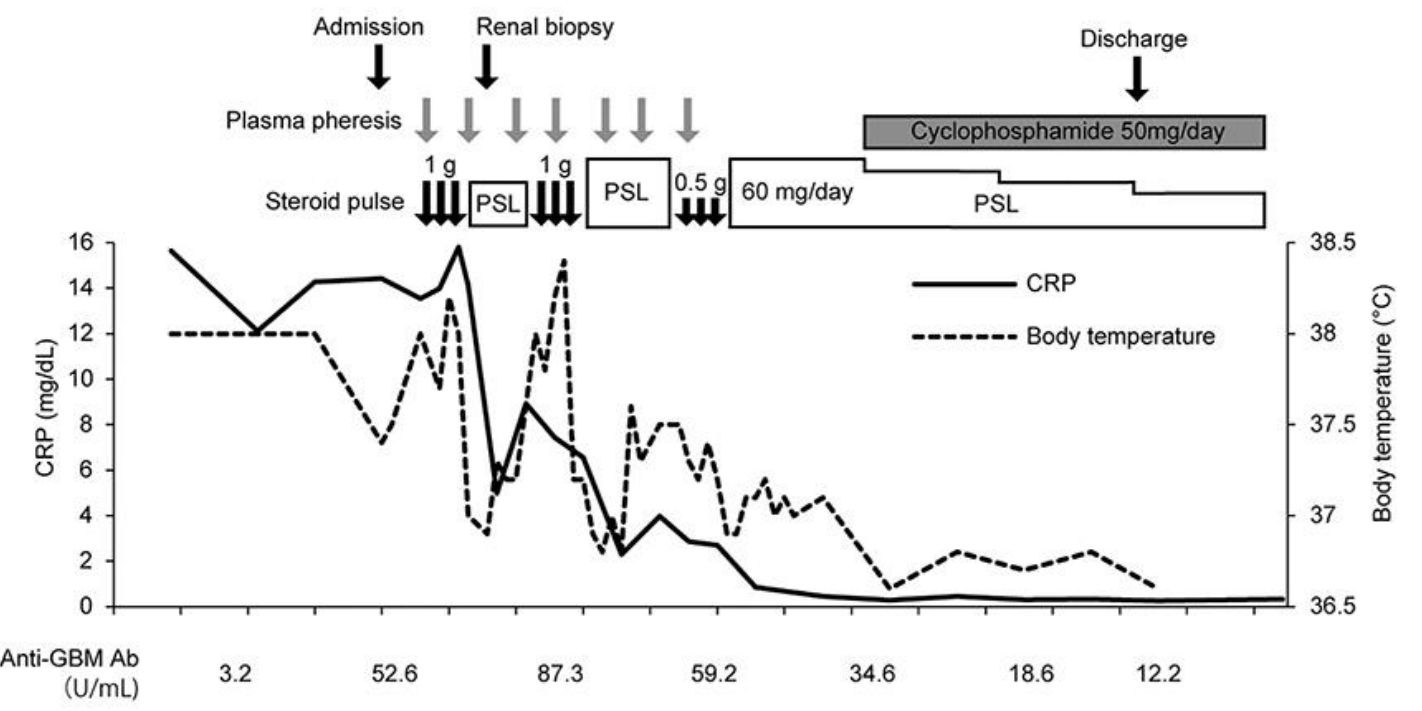

Macrohematuria

Toyota et al.: Nephritis with Delayed Appearance of Anti-Glomerular Basement Membrane Antibody

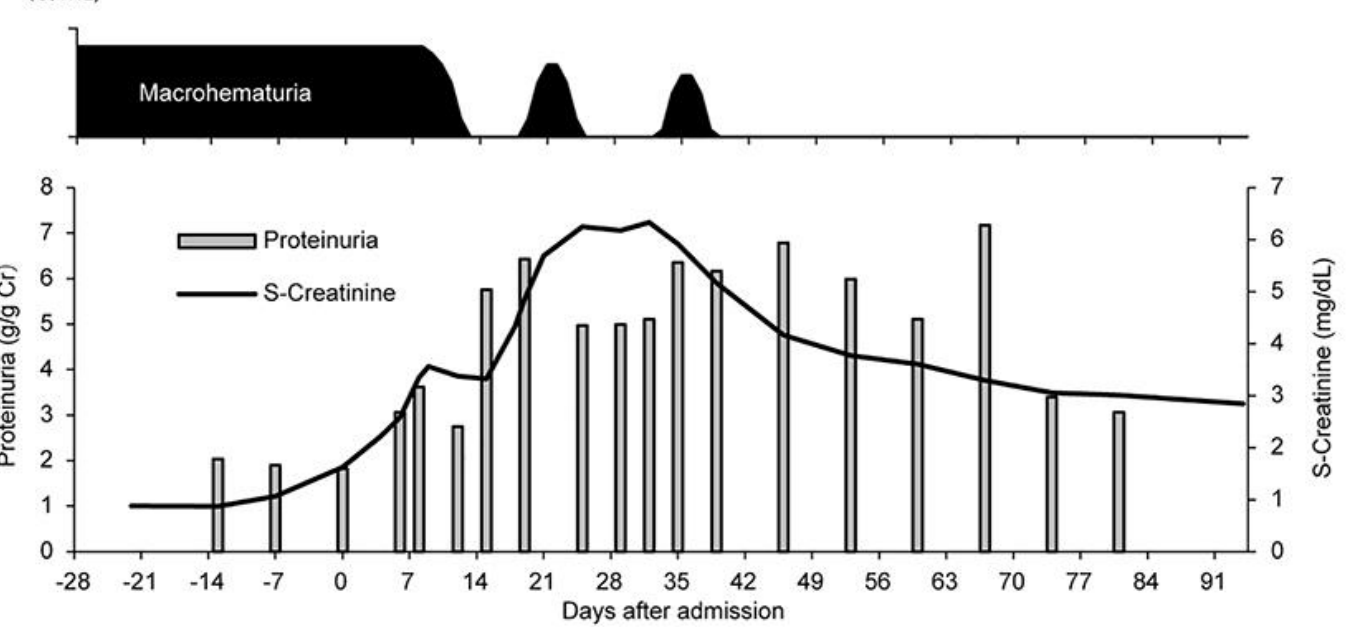

Fig. 1. Clinical course after the onset of anti-GBM glomerulonephritis. PSL, prednisolone; CRP, C-reactive protein. 


\section{Case Reports in Nephrology and Dialysis}

Case Rep Nephrol Dial 2019;9:25-32 DOI: $10.1159 / 000499401$ (c) 2019 www.karger.com/cnd

Toyota et al.: Nephritis with Delayed Appearance of Anti-Glomerular Basement Membrane Antibody

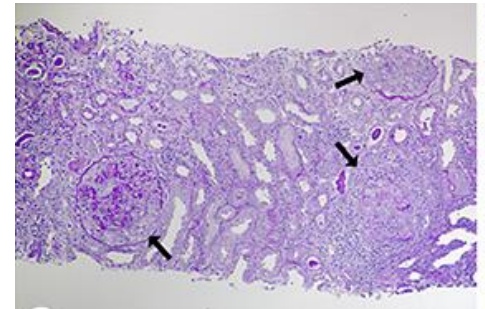

a

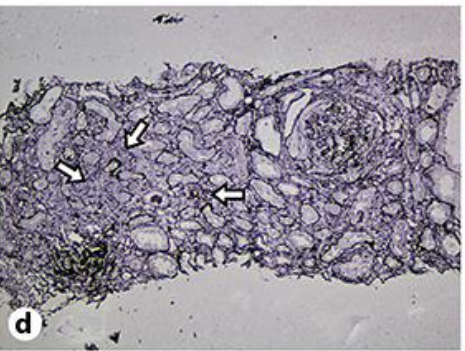

Subclass IgG2

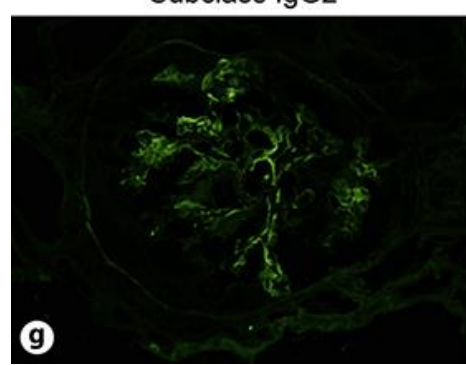

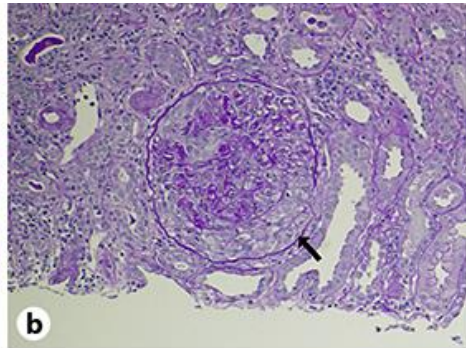

$\lg G$

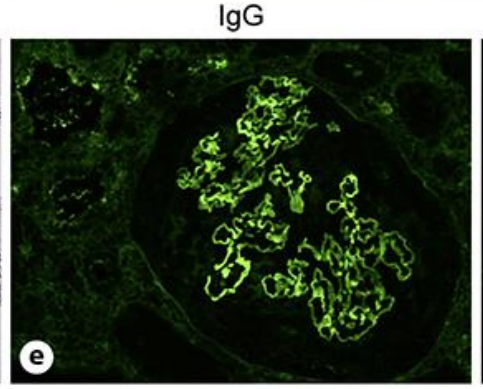

Subclass IgG3

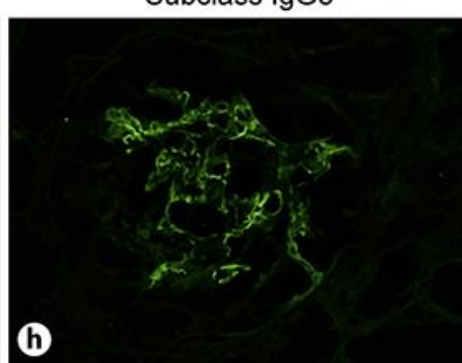

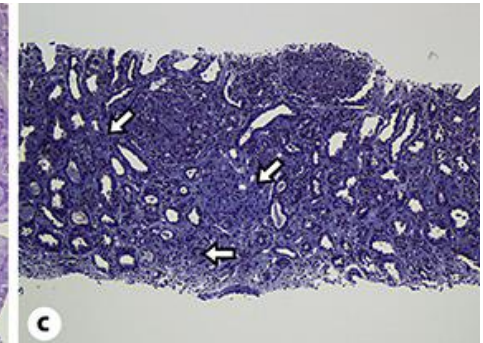

Subclass IgG1

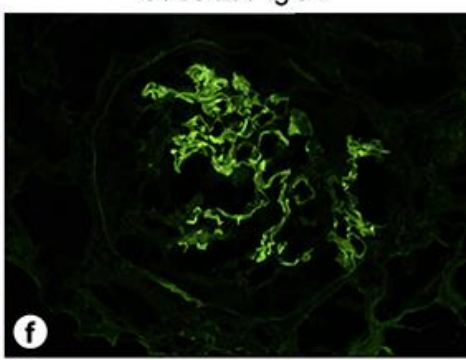

Subclass IgG4

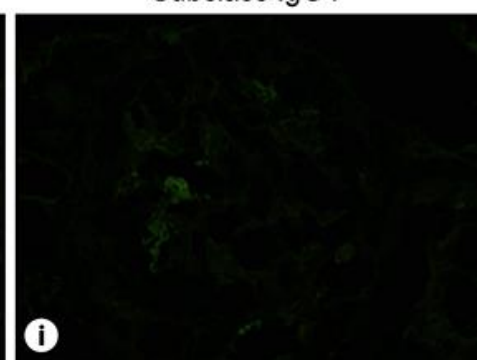

Fig. 2. Histological findings from renal biopsy. a Periodic acid-Schiff (PAS) staining image of a low-power field (magnification $\times 10$ ). b PAS staining of a high-power field (magnification $\times 20$ ). All the glomeruli were involved by "cellular" crescents (black arrows), which suggested that all the crescents were formed very recently. c Masson trichrome staining image (magnification $\times 10$ ). $d$ Periodic acid methenamine silver staining (magnification $\times 10$ ). White arrows indicate interstitial fibrosis and tubular atrophy. Inflammatory cell infiltration was detected in over $50 \%$ of the renal interstitium with moderate to severe interstitial fibrosis and tubular atrophy. e Immunostaining for immunoglobulin G (IgG) of a frozen section (magnification $\times 20) . \mathbf{f}-\mathbf{i}$ Immunostaining for IgG subclass. IgG1 is positive $(\mathbf{f}), \operatorname{IgG} 2$ and -3 are borderline positive $(\mathbf{g}, \mathbf{h})$, and IgG4 is negative (i). 